\title{
Grayson-Wilbrandt corneal dystrophy
}

INSERM

\section{Source}

INSERM. (1999). Orphanet: an online rare disease and orphan drug data base. GraysonWilbrandt corneal dystrophy. ORPHA:293375

Grayson-Wilbrandt corneal dystrophy (GWCD) is an extremely rare form of corneal dystrophy characterized by variable patterns of opacification in the Bowman layer of the cornea which extend anteriorly into the epithelium with decreased to normal visual acuity. 